Research Article

\title{
Development and Application of Milk-Run Distribution Systems in the Express Industry Based on Saving Algorithm
}

\author{
Zhenlai You and Yang Jiao \\ School of Economics and Management, Yanshan University, Qinhuangdao, Hebei 066004, China \\ Correspondence should be addressed to Zhenlai You; yzlai@ysu.edu.cn
}

Received 9 December 2013; Revised 13 February 2014; Accepted 14 February 2014; Published 20 March 2014

Academic Editor: Huaiqin Wu

Copyright (c) 2014 Z. You and Y. Jiao. This is an open access article distributed under the Creative Commons Attribution License, which permits unrestricted use, distribution, and reproduction in any medium, provided the original work is properly cited.

This paper introduces the milk-run schema into the express distribution logistics through the feasibility analysis of application of cyclic goods-taking schema in the express industry. In order to reach fully loaded as far as possible in distribution, the article improves the traditional model, adopting multi-objective decision and conforming constraint conditions to Milk-run schema, even approximating the practical truth solves model through the C-W saving algorithm. It can effectively shorten the distance and Lower costs by means of reasonable route planning. Finally, the paper has verified the model and its effectiveness of arithmetic application by means of cases analysis.

\section{Introduction}

Cyclic goods taking, also called Milk-run, originates from northern pasture of the United Kingdom and is a kind of transportation and delivery way, which is created for solving the problems of transportation and delivery of milk. Trucks transport bottles filled with milk to every gate in accordance with the routes predesigned by the law of intelligent vehicle path planning and collect the empty bottles on the back way to milk house [1]. After this, this goods-taking schema is applied to production, distribution, and other activities in every walk of life [2].

Milk-run model in the earliest was used in automobile manufacturing enterprises in the domestic. Scholars carried out related research of milk-run model in automotive industry in the theoretical and practical aspects $[3,4]$. We write this paper to research the milk-run model and improve algorithm on vehicle scheduling problem $(\mathrm{VwSP})$ and vehicle routing problem (VRP). Afterwards, third-party logistics companies provide on-time delivery service and add the time window constraints in the Milk-run model when they join in the express industry [5]. In applying research on milkrun model in domestic, $\mathrm{Xu}$ writes an article introducing the advantages, processes, and responsibilities of milk-run model and analyzing how to design the route and to determine the parameters of transport vehicles [6].

Foreign Milk-run model application study is not only used in the automotive industry but also in convenience groups such as the famous company 7-Eleven. In theoretical research, Chopra and Meindl divided the logistics system into four parts in 2006, respectively, as direct shipping, milkrun, cross docking, and tailored network, and the milk-run model belongs to one of the four kinds of logistics systems [7]. Du et al. studied the parameter setting of real-time vehicle distribution system based on milk-run model [8].

As an advanced distribution schema, milk-run is applied to logistics activities of various industries [9]. However, not so many researches of milk-run has applied in express industry. This paper puts forward some late-model express distribution schema applying milk-run schema by means of researching current situation of express industry and distribution schema. The schema combines advantages of Milk-run schema and practical truth of express distribution and saves logistics cost by means of optimizing distribution schema under the premise of satisfying timely and effective express service. On the design of milk-run module, the module of this paper is 
different from traditional distribution module. It relies on the reality and makes it more feasible. This module highlights the characteristics of milk-run and defines the size and weight of back and forth. Solving the smallest distance and the lowest cost minimum target not only ensure the effectiveness of express delivery, but also ensure lower cost of the express companies.

\section{Feasibility Analysis of Milk-Run in Express Delivery Industry}

Faced with the situation that the competition of express delivery industry becomes increasingly fierce, only keeping its feet in the market, enterprises need to squeeze logistics cost. However, a majority of express delivery industries do not form a scale, and they still adopt the old-fashioned delivery methods without planning. This leads to rare express companies forming large scale and owning international competitiveness in express enterprises of China. Meanwhile, due to being ignorant of how to improve logistic efficiency and how to reduce logistics cost, there is a large gap between internal and external quality of service [10, 11]. So, it is reducing logistics cost and improving quality of service at the same time to get a leg up on this competition. The combination between Milk-run schema and express industry can promote benign development of express enterprises.

2.1. Improving the Vehicle Load Factors and Reducing Transportation Cost. The main purpose of Milk-run model is to make full use of vehicles' space and tries to deliver the full loaded goods to designated place [12]. Considering cycletaking cargo and express delivery industry effective union, the vehicle can be make full use of space, greatly improve the vehicle's load factors, and avoid the waste of empty vehicles. At the same time, through effective path planning, it can not only shorten the distribution distance, reduce the reciprocating weeks to return the goods in transit and avoid the waste of time on the way, but also save the cost of transportation. The time and cost as the main competitive factors of express delivery industry play a vital role [13].

2.2. Promoting the Establishment and Perfection of Information Platform. Nowadays, information technology has a pivotal position in all walks of life. Milk-run requests logistics center and each distribution point to fully share information and requires its information with high accuracy, so logistics center can arrange distribution reasonably according to the information accurately planning the path. In the process, as the role of information to link the things together becomes more and more obvious, the construction of the integration of network information platform in the Courier industry can give full play to the cycle trend of pickup advantage [14]. At the same time, in the process of implementation of information management, circulation pickup pattern application also will continue to promote the perfection of information platform.

2.3. Improving the Efficiency and Quality of Service. In the process of Milk-run, the processing time of ship discharge the cargo will be increased, efficiency will be reduced, delivery time will be delayed, and even quality of service will be affected if there is no regular standard [15]. Therefore, in order to avoid unnecessary waste in process of delivery, establishing a unified standard to express mail packing process of enterprises not only makes loading and moving more convenient but also arranges vehicle load space reasonably. Standardized operation could decrease its fault rate, as well as improving staff quality and quality of service, even the whole enterprises.

\section{Establishment of Milk-Run Delivery Schema}

The model's parameters are defined follows:

$k$ : the number of vehicle, $k=1,2, \ldots, n$,

$V_{k}$ : the rated volume of vehicle $k$,

$i$ : transportation node number, $i=1,2,3, \ldots, l$,

$i=0$ : distribution center,

$W_{i}$ : the rated load of vehicle $k$,

$d_{i j}$ : the transport distance of node $i$ to node $j$,

$V_{i}$ : the volume of the goods delivered to the node $i$,

$V_{i}^{\prime}$ : the volume of the goods received by the node $i$,

$W_{i}$ : the weight of the goods delivered to the node $i$,

$W_{i}^{\prime}$ : the weight of the goods received by the node $i$,

$c_{1}$ : the vehicle transportation cost of per unit distance,

$c_{2}$ : represents vehicle fixed cost of each use,

$V_{k}$ : the biggest cargo volume of vehicle $k$,

$W_{k}$ : represents the biggest cargo weight of vehicle $k$,

$$
\begin{aligned}
& y_{k j}= \begin{cases}1 & \text { if The task of } i \text { is } \\
& \text { performed by vehicle } j \\
0 & \text { otherwise; }\end{cases} \\
& x_{i j k}= \begin{cases}1 & \begin{array}{l}
\text { if Vehicle } k \text { from client } i \\
\text { drive to customer } j \\
0 \quad \text { otherwise }
\end{array}\end{cases}
\end{aligned}
$$

Then we establish the model opt

$$
\begin{aligned}
& \min z_{1}=\sum_{i=0}^{L} \sum_{j=0}^{L} \sum_{k=0}^{L} d_{i j} x_{i j k} \\
& \min \quad z_{1}=\sum_{i=0}^{L} \sum_{j=0}^{L} \sum_{k=0}^{L} d_{i j} x_{i j k} c_{1}+n c_{2}
\end{aligned}
$$



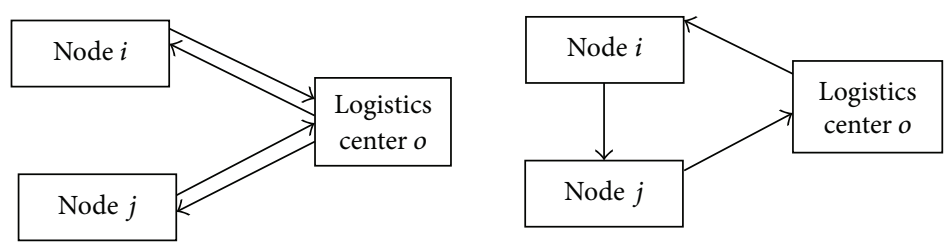

FIGURE 1: The principle diagram of the saving algorithm.

$$
\begin{gathered}
1 \leqslant \sum_{k=1}^{K} y_{k i} \leqslant 2 \quad i=1,2, \ldots, l \\
\sum_{k=1}^{n} \sum_{j=0}^{L} x_{i j k}=\sum_{k=1}^{n} y_{k i} \quad i=1,2, \ldots, l \\
\sum_{k=1}^{n} \sum_{j=0}^{L} x_{i j k}=\sum_{k=1}^{n} y_{k j} \quad j=1,2, \ldots, l \\
\sum_{j=0}^{l} x_{0 j k}=\sum_{j=0}^{l} x_{j 0 k} \leqslant 1 \\
\sum_{i=0}^{n} V_{i}^{\prime} y_{k i}=\sum_{i=n+1}^{l} V_{i} y_{k i} \leqslant V_{k} \\
\sum_{i=0}^{n} W_{i}^{\prime} y_{k i}=\sum_{i=n+1}^{l} W_{i} y_{k i} \leqslant W_{k} .
\end{gathered}
$$

Formulas (2) and (3) are the objective function. The objective of the model is the smallest total distance and transportation cost. Constraint formula (4) represents each node having vehicle service, and at most two vehicles serve the same node. Formulas (5) and (6) represent the effectiveness of vehicle arrival. It means that a vehicle reaches a node that can be served. Formula (7) indicates that, as long as the task is completed, the vehicle must return to the distribution center. Formulas (8) and (9), respectively, represent the load and volume constraints. Each node can only be served by one vehicle in the traditional model's constraint. However, when you solve the model, you may obtain a nonoptimal solution. Theoretically, the total number of vehicles is required in the plan formula (10):

$$
\begin{aligned}
& n=\max \left\{\left[\frac{\sum_{i=0}^{L} W_{i}}{W_{k}}\right],\left[\frac{\sum_{i=0}^{L} W_{i}^{\prime}}{W_{k}}\right],\right. \\
& {\left.\left[\frac{\sum_{i=0}^{L} V_{i}}{v_{k}}\right],\left[\frac{\sum_{i=0}^{L} V_{i}^{\prime}}{V_{k}}\right]\right\} . }
\end{aligned}
$$

As each node has only one vehicle for service due to the traditional model solution, so that all the cargo at each node can only be installed in one vehicle. Even if the vehicle is not fully loaded, if a node cannot be one-time carried the residual cargo, the vehicle must return distribution centers. In this model, the service at each node is not limited to one vehicle; the vehicle can be achieved load in the process.

\section{Model Solution}

Milk-run model is a typical NP-hard problem; for such problems, using the exact algorithm to obtain the global optimal solution is more difficult, and the amount of calculation will increase with the size of the problem increasing exponentially $[16,17]$. Therefore, the current path for such a large-scale problem is more inclined to use heuristic algorithms for solving them, not to bothering to solve the problem of the exact optimal solution, but stressing to obtain satisfactory solution by reducing the computational complexity [18-20].

Including a variety of heuristic algorithms, this paper uses the CW saving algorithm to solve the model. The core idea is to calculate the saving distance because of merging two paths, according to the value of savings to merge the two paths until the vehicle is full-loaded, and then using the second vehicle on the same way until all goods are delivered to designated location.

In Figure 1, when the logistics center distributes goods to $i$ and $j$, respectively, the shortest distance of the line $i$ is defined as $d_{i}=d_{i o}+d_{o i}$ and the shortest distance of the line $j$ is defined as $d_{j}=d_{j o}+d_{o j}$. Connecting the line $i$ and $j$, using the same vehicle for shipment, the transportation distance is defined as $d_{i j o}=d_{o i}+d_{o j}+d_{i j}$. In this case, the transport distance of saving is defined as $\Delta d=2 d_{o i}+2 d_{o j}-\left(d_{o i}+d_{o j}+d_{i j}\right)=$ $d_{o i}+d_{o j}-d_{i j}$ (the formula of savings in transport). Obviously, it also saves the use of one vehicle at this time, effectively reducing the use of vehicles fixed costs and transportation costs.

The step of improved saving algorithm is defined as follows.

Step 1. Calculate the savings value of the distance between each node by using the formula of savings in transport. Then list the saving distance matrix $\left[\Delta d_{i j}\right]$.

Step 2. Order the $\Delta d_{i j}$ by ascending order.

Step 3. Analyze array $\left[\Delta d_{i j}\right]$, exit the cycle if it is empty set; otherwise, choose the maximum saving value of the two distribution nodes $i$ and $j$ and judge whether the two nodes are satisfied by the following conditions.

The nodes $i, j$ are not in the line which has been constructed.

The node $i$ or $j$ is in the line which has been constructed, and it is directly connected with the logistics center.

The nodes $i$ and $j$ are, respectively, in two different lines which have been constructed and directly connected with the logistics center. If nodes $i$ and $j$ fulfilled the above conditions, go to Step 4. 
Step 4. Calculate the volume and weight of goods of two nodes which are distributed and selected. If the volume or weight is not beyond the vehicles' constraint, connect $i$ and j; otherwise, turn to Step 5.

Step 5. Connect $i, j$ nodes and determine whether there is a splitting case, if so, the vehicle is loaded to the fullshipped back to the logistics center, connect $i$ and $j$ node and determine whether there is splitting case, if so, the vehicle can be loaded to full shipped back to the logistics center, and complete the cycle of the vehicle $\mathrm{k}$ update the information of the remaining cargo, then the distribution of node will be in the next cycle. Otherwise, the cargo of $i$ and $j$ can be completed by one vehicle and turn to Step 6.

Step 6. Select the remaining delivery node for the maximum saving value and go to Step 3 .

The result of traditional models uses the savings algorithm to obtain the scheduling of the vehicles as shown in Table 3.

\section{Case Study}

Courier Company W is a private express delivery company in China; in the process of the development, the enterprise recognizes the importance of management, advances technology, and begins to introduce advanced management concepts and automated technology. With the increasing competition in the courier industry, companies, who can stand out in force in the cornier industry, become increasingly aware of the need to improve internal courier safety, efficiency, and low cost. In this paper, $\mathrm{W}$ express company introduces that milk-run model is the background and collects and analyzes the statistical data of a certain region. The introduction of milk-run model effectively reduces logistics costs, improves the vehicle's load factor, and reduces unnecessary waste.

5.1. W's Introduction to the Basic Situation. W's has ten distribution points in a region, where the location of the distribution is shown in Figure 2.

For example, extracting the data on March 1, 2012, the information of the goods delivered to the distribution center and received from the every distribution node is shown in Table 1.

The maximum cargo volume of delivery vehicles is 10 and the biggest loading capacity is 2.5 tons. Vehicle unit distance transport cost is 20 yuan $/ \mathrm{km}$, and the fixed cost of one vehicle is 400 yuan (RMB). According to the weight and volume of distribution and without taking into accounts the information of received goods before applying the Milkrun model, the enterprise designs a distribution route. All the goods will be delivered to the designated distribution node, and then the goods will be collected back to the distribution center in original way. The traditional models are often applied to the situation that the vehicle achieves its full load, but there also some other goods that cannot be loaded, or the vehicle's empty load rate is relatively high. For example, the quantity of goods to be shipped to distribution center of the line $0-3-7-0$ distribution is 2.8 tons, while it is exceeding

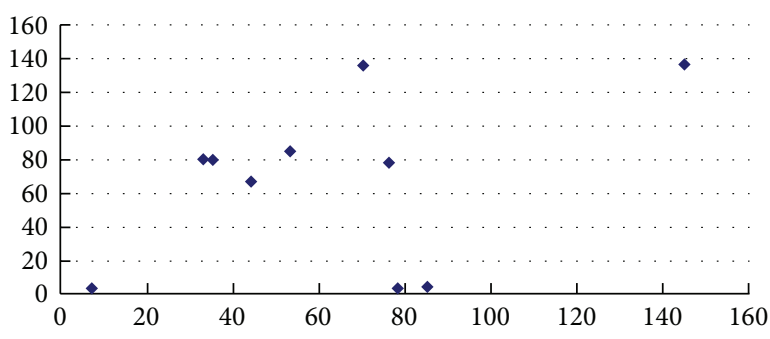

FIGURE 2: The layout of $\mathrm{W}$ company distribution node in a given area.

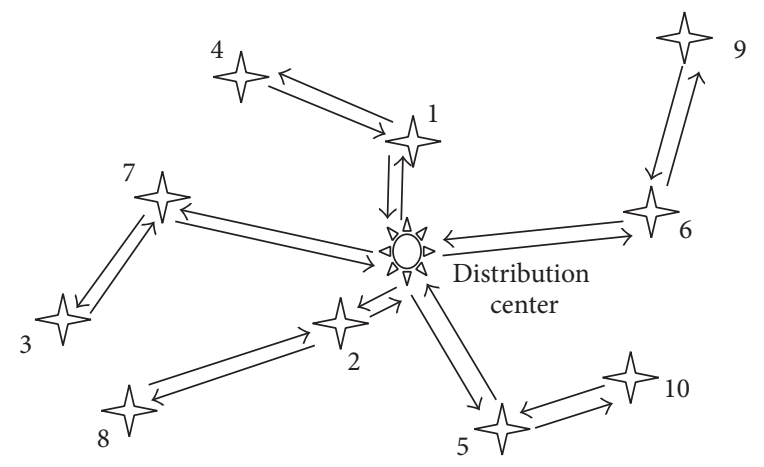

FIgURE 3: The distribution path graph before the optimization.

the maximum load of the vehicle; the company's approach is to wait until the next day to dispose the remainder. It not only leads to increased logistics costs but also reduces the efficiency of the express company. The company can not meet customers need in time and has a disadvantage in time benefit. W's delivery rote before taking milk-run model is shown in Figure 3. It needs five vehicles to complete the task, for a total driving distance of $75.48 \mathrm{~km}$.

Adopt saving algorithm model, and the distance matrix of the distribution node is shown in Table 2.

The vehicle scheduling and optimized path are shown in Table 4 by using improved savings algorithm.

The optimized path is shown in Figure 4 according to the optimized route and vehicle scheduling information.

The result is based on saving algorithm: the cycle pickup uses a total of four vehicles, transporting a total distance of $64.58 \mathrm{~km}$, distribution and transportation actual average loading rate of 84 percent, and actual average loading rate of 99 percent, and for a total average effective loading was 91.5 percent. Compared to the original model of transport, less use of a truck, the actual loading rate has been improved to avoid the condition of delaying caused by not meeting the requirements. The benefit of milk-run model that contrasts with the previous models is shown in Table 5.

We can clearly see the significant efficiency gains by optimizing path route in taking milk-run model from the table. Fewer vehicles, shortened transport distance, improved load factor, all of that reduce the cost of logistics enterprises and improve the efficiency to some extent. Meanwhile, it can avoid the delay of goods and ensure the goods to be instantly 
TABLE 1: W companys deliver goods information in a given area.

\begin{tabular}{|c|c|c|c|c|c|}
\hline $\begin{array}{l}\text { Distribution } \\
\text { node no. }\end{array}$ & $\begin{array}{l}\text { Coordinates of } \\
\text { supplier }\end{array}$ & $\begin{array}{l}\text { Weight of the } \\
\text { delivered goods }(t)\end{array}$ & $\begin{array}{c}\text { Volume of } \\
\text { delivered goods }\left(\mathrm{m}^{3}\right)\end{array}$ & $\begin{array}{l}\text { Weight of } \\
\text { received goods }(t)\end{array}$ & $\begin{array}{c}\text { Volume of } \\
\text { received goods }\left(\mathrm{m}^{3}\right)\end{array}$ \\
\hline 1 & $(35,80)$ & 0.8 & 3.5 & 0.6 & 1.7 \\
\hline 2 & $(44,67)$ & 1.2 & 3 & 0.4 & 2.8 \\
\hline 3 & $(76,78)$ & 0.3 & 3.2 & 1.9 & 4.6 \\
\hline 4 & $(33,80)$ & 1.2 & 4.3 & 1.6 & 3.4 \\
\hline 5 & $(78,3)$ & 0.7 & 2.2 & 1.1 & 2.9 \\
\hline 6 & $(53,85)$ & 1.1 & 2.1 & 1.8 & 2.7 \\
\hline 7 & $(70,136)$ & 0.7 & 2.3 & 0.9 & 2.7 \\
\hline 8 & $(7,3)$ & 0.2 & 1.1 & 0.7 & 2.1 \\
\hline 9 & $(145,137)$ & 1.3 & 2.2 & 0.7 & 1.2 \\
\hline 10 & $(85,4)$ & 0.9 & 3.1 & 0.2 & 2.1 \\
\hline
\end{tabular}

TABLE 2: Distance matrix of the distribution node.

\begin{tabular}{ccccccccccc}
\hline & 0 & 1 & 2 & 3 & 4 & 5 & 6 & 7 & 8 & 9 \\
\hline 0 & 0 & & & & & & & & & \\
1 & 1.66 & 0 & & & & & & & \\
2 & 0.1 & 1.58 & 0 & & & & & & \\
3 & 3.42 & 4.1 & 3.38 & 0 & & & & & \\
4 & 1.78 & 0.2 & 1.7 & 4.3 & 0 & & & & \\
5 & 7.16 & 8.82 & 7.25 & 7.5 & 8.92 & 0 & & & \\
6 & 2.1 & 1.87 & 2.01 & 2.4 & 2.06 & 8.57 & 0 & & \\
7 & 7.47 & 6.6 & 7.37 & 5.83 & 6.71 & 13.32 & 5.38 & 0 & & \\
8 & 7.31 & 8.19 & 7.39 & 10.19 & 8.13 & 7.1 & 9.4 & 14.72 & 0 & \\
9 & 12.35 & 12.39 & 12.29 & 9.08 & 12.57 & 14.98 & 10.57 & 7.5 & 19.24 & 0 \\
10 & 7.43 & 9.1 & 7.52 & 7.45 & 9.21 & 0.71 & 8.71 & 13.28 & 7.8 & 14.59 \\
\hline
\end{tabular}

TABLE 3: The path and scheduling information of vehicles before optimization.

\begin{tabular}{|c|c|c|c|c|c|c|}
\hline Vehicle & Vehicle path & $\begin{array}{c}\text { Total transportation } \\
\text { distance }\end{array}$ & $\begin{array}{c}\text { Weight of } \\
\text { distribution }(t)\end{array}$ & $\begin{array}{c}\text { Volume of } \\
\text { distribution }\left(\mathrm{m}^{3}\right)\end{array}$ & $\begin{array}{l}\text { Weight of } \\
\text { received }(\mathrm{t})\end{array}$ & $\begin{array}{c}\text { Volume of } \\
\text { received }\left(\mathrm{m}^{3}\right)\end{array}$ \\
\hline 1 & $0-5-10-8-0$ & 22.06 & 1.8 & 6.4 & 2 & 7.1 \\
\hline 2 & $0-7-9-0$ & 27.32 & 2 & 4.5 & 1.6 & 3.9 \\
\hline 3 & $0-1-4-0$ & 3.64 & 2 & 7.8 & 2.2 & 5.1 \\
\hline 4 & $0-2-6-0$ & 4.21 & 2.3 & 5.1 & 2.2 & 5.5 \\
\hline 5 & $0-3-0$ & 6.84 & 0.3 & 3.2 & 1.9 & 4.6 \\
\hline
\end{tabular}

TABLE 4: Vehicle scheduling information and optimized path.

\begin{tabular}{lcccccc}
\hline Vehicle & Vehicle path & $\begin{array}{c}\text { Total transportation } \\
\text { distance }\end{array}$ & $\begin{array}{c}\text { Weight of } \\
\text { distribution }(\mathrm{t})\end{array}$ & $\begin{array}{c}\text { Volume of } \\
\text { distribution }\left(\mathrm{m}^{3}\right)\end{array}$ & $\begin{array}{c}\text { Weight of } \\
\text { receival }(\mathrm{t})\end{array}$ & $\begin{array}{c}\text { Volume of } \\
\text { receival }\left(\mathrm{m}^{3}\right)\end{array}$ \\
\hline 1 & $0-10-5-8-2-0$ & 23.16 & 1.8 & 6.4 & 2.4 & 9.9 \\
2 & $0-7-9-3-0$ & 27.47 & 2.3 & 7.7 & 2.5 & 6.5 \\
3 & $0-4-1-6-0$ & 6.02 & 2 & 8.4 & 2.5 & 5.8 \\
4 & $0-3-6-2-0$ & 7.93 & 2.3 & 4.5 & 2.5 & 5 \\
\hline
\end{tabular}

TABLE 5: The contradistinction between milk-run model and the previous model of W's.

\begin{tabular}{lccccc}
\hline Transportation schema & $\begin{array}{c}\text { Vehicle } \\
\text { usage }\end{array}$ & $\begin{array}{c}\text { Total transportation } \\
\text { distance }(\mathrm{km})\end{array}$ & $\begin{array}{c}\text { Vehicle loaded } \\
\text { rate }(\%)\end{array}$ & $\begin{array}{c}\text { Transportation task } \\
\text { completion }\end{array}$ & $\begin{array}{c}\text { Transportation cost } \\
\text { (Yuan) }\end{array}$ \\
\hline Normal schema & 5 & 86.92 & 74.80 & unfinished & 3738.4 \\
Milk-run schema & 5 & 64.07 & 73.20 & finished & 3281.4 \\
Improved milk-run schema & 4 & 64.58 & 91.50 & finished & 2891.6 \\
\hline
\end{tabular}




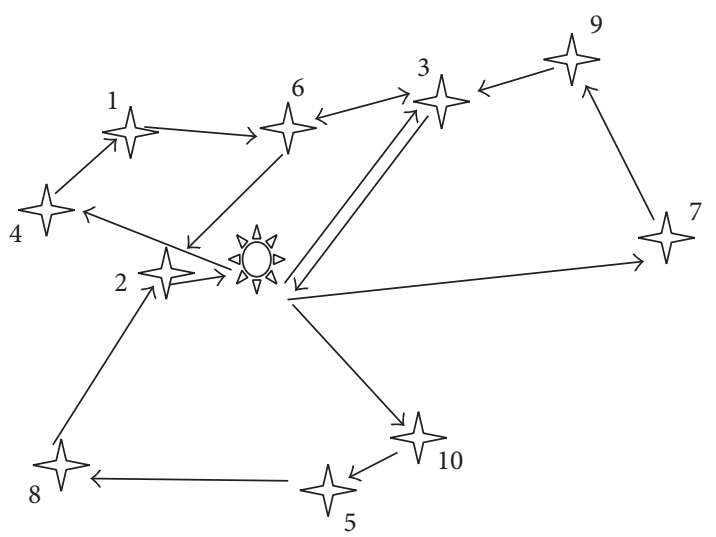

FIgURE 4: Optimization of path graph.

and accurately transported, finally it will reduce the cost of its time and enhance the W's competitive advantage over time.

\section{Conclusion}

This paper introduces the application of milk-run schema to express delivery industry and establishes a multiobjective path optimization schema, which has the shortest distance and the lowest cost. Through the case analysis results, we can conclude that milk-run model applied to express delivery industry can improve load factors, shorten shipment distance, advance time efficiency, fulfill transport demand, and reduce logistics transportation cost. However, compared with complexity of having impact on logistics transportation factors, this schema is relatively simple and time window and environmental logistics concept will be added in schema in the further research and the schema will tend to be more accurate and practical.

\section{Conflict of Interests}

The authors declare that there is no conflict of interests regarding the publication of this paper.

\section{Acknowledgment}

The authors would like to thank the Natural Science Foundation of Heibei Province (no. G2013203385) for supporting this work.

\section{References}

[1] I. Satoh, "A formal approach for Milk-run transport logistics," IEICE Transactions on Fundamentals of Electronics, Communications and Computer Sciences, vol. E91.A, no. 11, pp. 3261-3268, 2008.

[2] Y. Zimeng, H. Yanguang, and J. Hui, “The Optimization simulation of Milk-run model on aviation spare parts," Science Technology and Engineering, vol. 1, pp. 37-41, 2012.

[3] L. Liu and X. W. Tang, "A study on vendors lead time decision model," Systems Engineering, vol. 23, no. 8, pp. 42-45, 2005.
[4] S. J. Sadjadi, M. Jafari, and T. Amini, "A new mathematical modeling and a genetic algorithm search for Milk run problem (an auto industry supply chain case study)," International Journal of Advanced Manufacturing Technology, vol. 44, no. 1-2, pp. 194-200, 2009.

[5] T. Du, F. K. Wang, and P. Y. Lu, "A real-time vehicle-dispatching system for consolidating Milk runs," Transportation Research E, vol. 43, no. 5, pp. 565-577, 2007.

[6] X. Qiuhua, "The practice and application of Milk-run model at Shanghai GM," Automobile and Parts, vol. 3, pp. 21-24, 2003.

[7] S. Chopra and P. Meindl, Supplier Chain ManagementStrategies, Planning, and Operation, Tsinghua University Press, Beijing, China, 2006.

[8] T. Du, F. K. Wang, and P. Y. Lu, "A real-time vehicle-dispatching system for consolidating Milk runs," Transportation Research E, vol. 43, no. 5, pp. 565-577, 2007.

[9] H. Kilic, M. Durmusoglu, and M. Baskak, "Classification and modeling for in-plant Milk-run distribution systems," International Journal of Advanced Manufacturing Technology, vol. 62, no. 9-12, pp. 1135-1146, 2012.

[10] G. Faxia and L. Shaoke, "Discussion of the private courier industry problems and countermeasures," Hebei Transportation Research, vol. 02, pp. 65-68, 2010.

[11] Y. Jingdong, S. Yinping, and L. Qian, "Chinas express delivery industrys current situation, problems and countermeasures," China Science and Technology Information, vol. 18, pp. 205-207, 2008.

[12] N. Arvidsson, “The Milk run revisited: a load factor paradox with economic and environmental implications for urban freight transport," Transportation Research A, vol. 51, pp. 56-62, 2013.

[13] M. Holweg and J. Miemczyk, "Delivering the "3-day car"the strategic implications for automotive logistics operations," Journal of Purchasing and Supply Management, vol. 9, no. 2, pp. 63-71, 2003.

[14] N. Kumar, "Supply chain design at jaguar: bring nirvana to halewood," Supply Chain Forum, vol. 3, no. 1, pp. 74-80, 2002.

[15] X. J. He, J. G. Kim, and J. C. Hayya, "The cost of lead-time variability: the case of the exponential distribution," International Journal of Production Economics, vol. 97, no. 2, pp. 130142, 2005.

[16] L. Jun, L. Xiebing, and G. Yaohuang, "Genetic algorithm of nonloaded vehicle scheduling problem," Systems Engineering Theory Methodology Applications, vol. 03, pp. 235-239, 2000.

[17] J. Chen and T. Wu, "Vehicle routing problem with simultaneous deliveries and pickups," Journal of the Operational Research Society, vol. 57, no. 5, pp. 579-587, 2006.

[18] N. A. Wassan, A. H. Wassan, and G. Nagy, "A reactive tabu search algorithm for the vehicle routing problem with simultaneous pickups and deliveries," Journal of Combinatorial Optimization, vol. 15, no. 4, pp. 368-386, 2008.

[19] J. Y. Potvin and S. Bengio, "The vehicle routing problem with time windows part II: genetic search," INFORMS Journal on Computing, vol. 8, no. 2, pp. 165-172, 1996.

[20] B. E. Gillett and L. R. Miller, "A heuristic algorithm for the vehicle dispatch problem," Opration Research, vol. 22, pp. 240$349,1974$. 


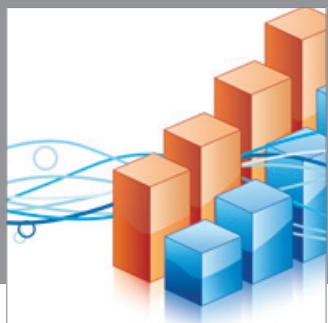

Advances in

Operations Research

mansans

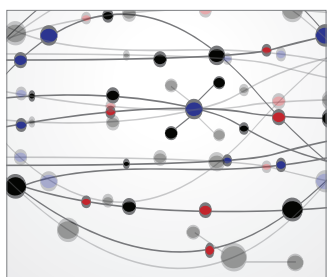

The Scientific World Journal
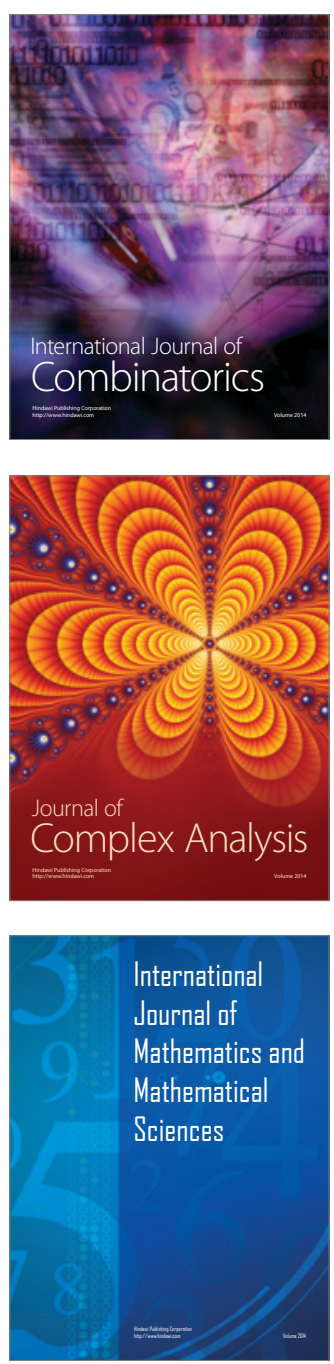
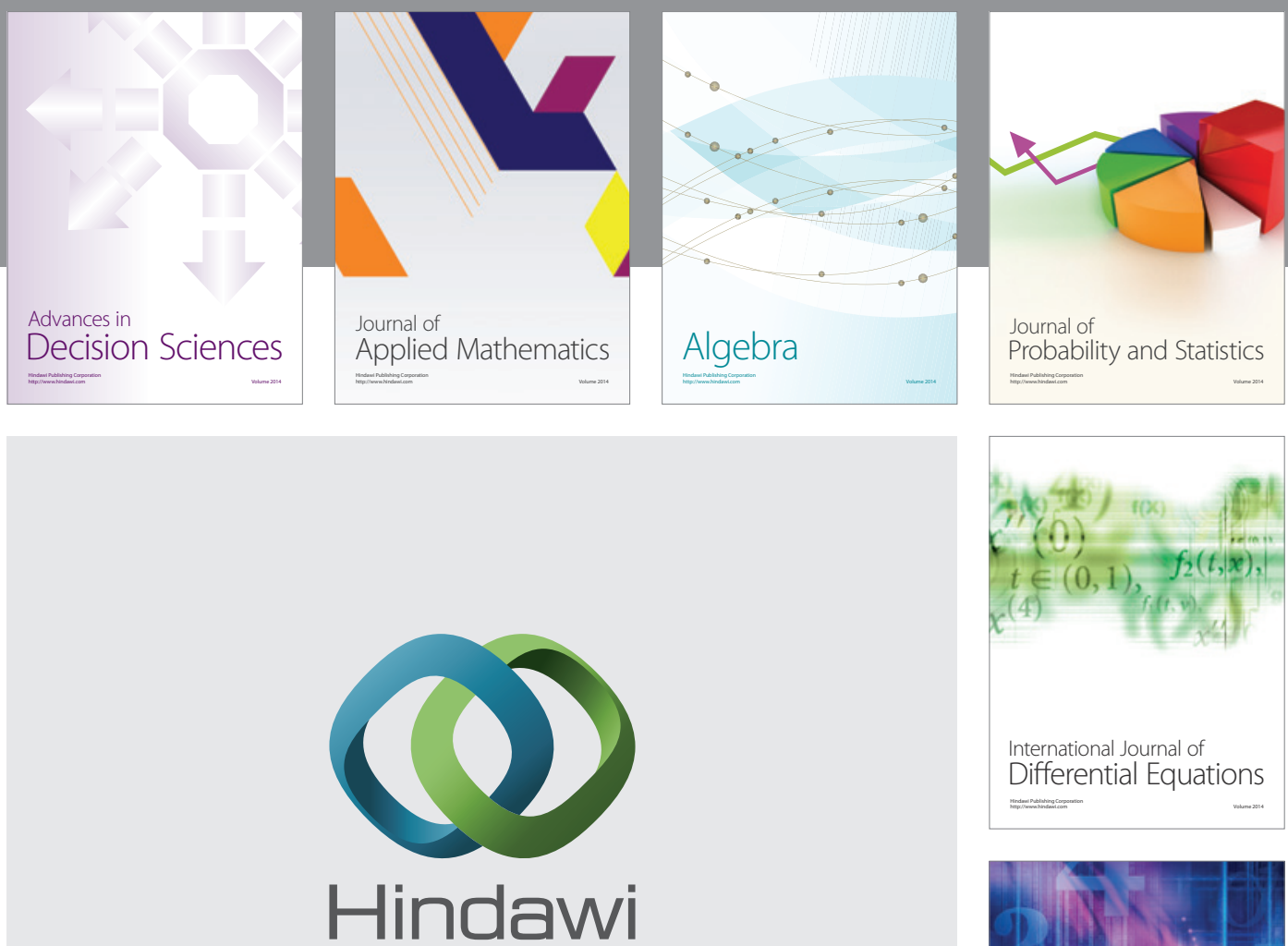

Submit your manuscripts at http://www.hindawi.com
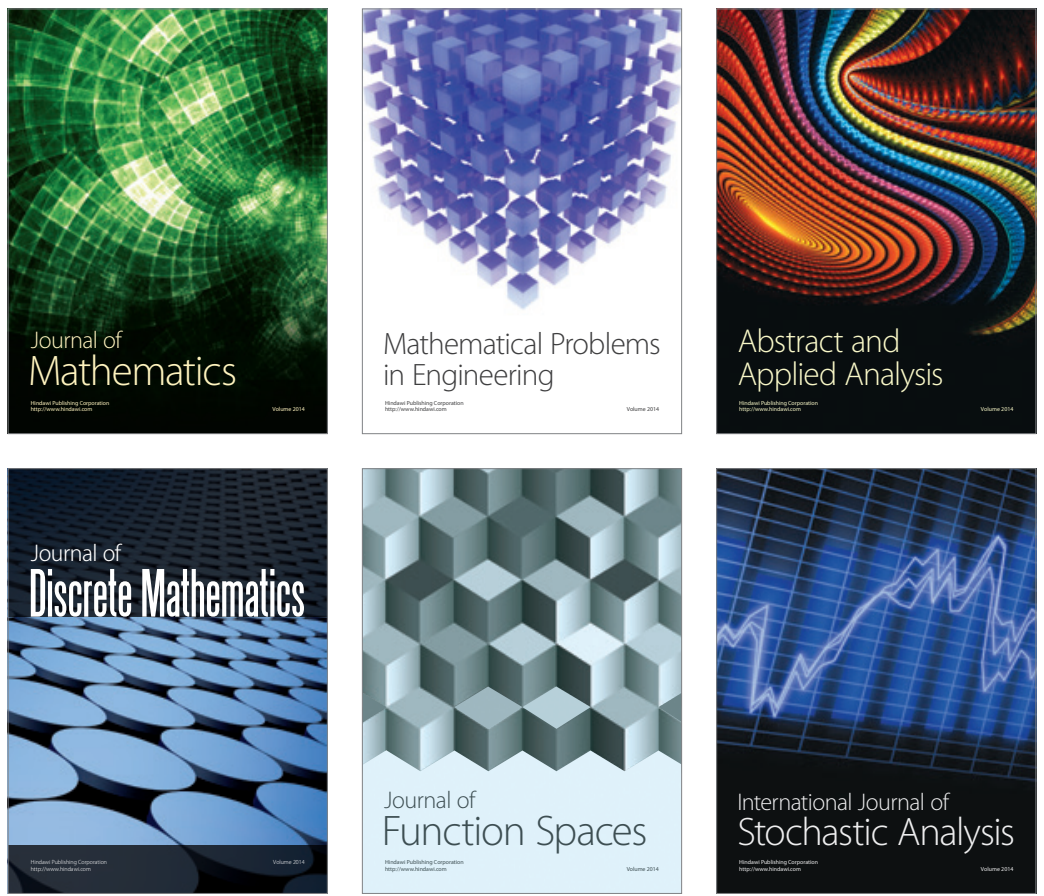

Journal of

Function Spaces

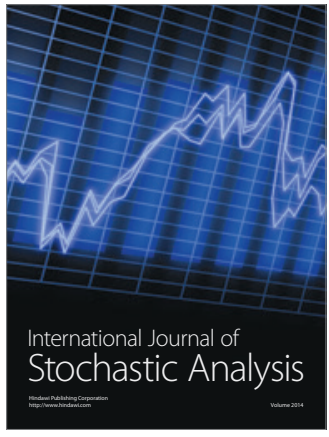

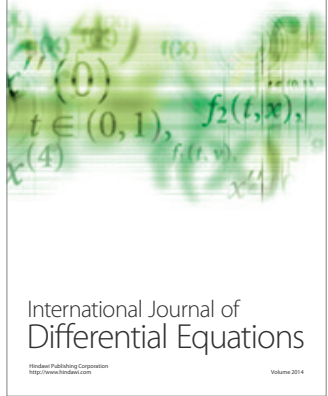
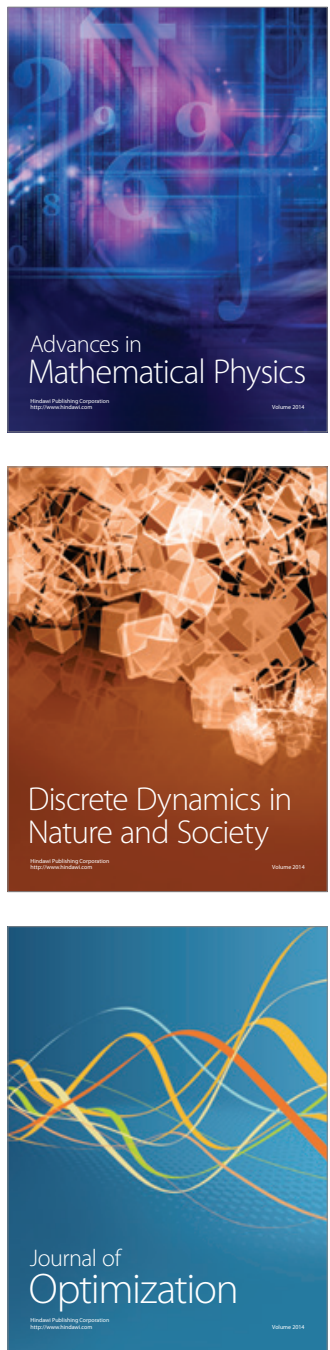